\title{
Comparison of Mechanical Properties of Carbon Fibre and Kaolin Reinforced Polypropylene Composites
}

\author{
Duriyang Thongsoon ${ }^{1 *}$, Chamil Abeykoon ${ }^{1}$, Ivan J. Vera-Marun ${ }^{2}$, Prasad Potluri ${ }^{1}$, \\ Wareerom Polrut $^{3}$, Butra Boonliang ${ }^{3}$ \\ ${ }^{1}$ Northwest Composites Centre, Department of Materials, The University of Manchester, Manchester, M13 9PL, UK, \\ duriyang.thongsoon@manchester.ac.uk: chamil.abeykoon@manchester.ac.uk \\ ${ }^{2}$ Department of Physics and Astronomy, The University of Manchester, Manchester, UK \\ ${ }^{3}$ SCG Chemicals Co., Ltd. Thailand
}

\begin{abstract}
This study aims to evaluate potential methodologies for improving the performance of polypropylene (PP) matrix composites by the addition of carbon fibre and kaolin fillers, processed using a twin screw extruder, and compare them with neat PP. The effect of filler types and loading was investigated on mechanical properties such as the tensile modulus, flexural modulus, and impact strength, evaluated by using universal testing systems. Of the two types of composites, carbon fibre reinforced composites gave the best performance. The results showed that the addition of $30 \mathrm{wt} \%$ of short carbon fibre to neat PP raised the tensile modulus and flexural modulus by $219 \%$ and $280 \%$, respectively, compared to neat PP itself. Also, the elongation at break was reduced by $87-96 \%$ compared to neat PP, which is attributed to such fillers restricting the chain mobility of polymer molecules. Addition of kaolin has also resulted in improved tensile and flexural modulus up to $42 \%$ and $41 \%$, respectively, from that of the neat PP. Izod impact test showed that the addition of kaolin also improves impact strength by up to $10 \%$ at low content of kaolin. However, the impact strength was reduced with increasing kaolin content above $20 \%$ by weight, due to the agglomeration of kaolin particles. For PP/carbon fibre composites, the impact strength slightly increased when increasing the carbon fibre content from $10 \mathrm{wt} \%$ to $20 \mathrm{wt} \%$, whereas it slightly dropped when increasing to $30 \mathrm{wt} \%$. Based on these results, overall, the addition of carbon fibre and kaolin from 10-30 wt $\%$ significantly improves the tensile and flexural modulus properties. These fillers can be considered as promising reinforcing materials to increase the performance of thermoplastics. These type of composite systems may encourage commodity thermoplastics to be applied for high-end applications at a significant rate in the near future.
\end{abstract}

Keywords: Polymer matrix composites, Carbon fibre/PP composite, Kaolin/PP composite

\section{Introduction}

Composites are becoming popular in wide range of applications due to their superior properties such as high specific strength, tailor-made properties, and fewer joints due to part unitization. However, plastic industry has multiple challenges yet to be addressed such as improving recycling procedures, characterization and durability of composites systems, and understanding of the possible failure mechanisms [1,2]. Reinforcing agents have become the second major component in the development process of polymeric materials. There are a plenty of reinforcing materials which have been studied to improve the performance of the matrix materials such as mechanical properties, dimensional stability, thermal resistance, etc $[3,4]$. In general, reinforcing agents are in the form of fibre, particles and flakes. Among the different fibres used in polymer matrix composites, carbon fibre is one of the most promising reinforcements in polymer matrix composites. There is a huge consumption for carbon fibre. The annual global demand for carbon fibre was expected to increase from 72,000 tons to 140,000 tons and the carbon fibre-reinforced composite global revenue expected to increase from 28.2 billion USD to 48.7 billion USD [5]. Given these considerations, carbon fibre has been selected in this study as a representative fibrous filler. For the particle family, fillers were considered either due to their huge consumption or for being interesting materials. Among the latter, kaolin was considered as the representative candidate in the particle family because it is a ubiquitous natural mineral which has been previously demonstrated to improve mechanical properties of polymers [6, 7].

\subsection{Previous Studies on PP/Carbon Fibre Composite}

Over the last few years, there has been great interest in carbon fibre-reinforced plastics for low-cost high-performance and lightweight structural applications, such as in aerospace, civil engineering and automotive industries, hence they have the potential to become one of the most important commercial materials in the near future [8-10]. However, even if short 
carbon fibres are currently available in the market, their usage has been restricted in some applications. The evaluation of mechanical properties of $\mathrm{PP} /$ carbon fibre composite in this study can enable the use of conventional plastics in high performance applications.

Nowadays, carbon fibres are commercially available to be used in PP composites that are produced in different forms, like homopolymer or copolymer PP composites [9]. Recently attention has been focused on improvement the performance of carbon fibre-reinforced PP based composites [8, 10-12]. Rocha et al. [8] revealed that Young's modulus of compression moulding samples was enhanced by up to $147 \%$ when adding $5 \mathrm{pph}$ (parts per hundred) of carbon fibre. Work by Altay et al. [10] showed that with addition of recycled carbon fibre up to $40 \mathrm{wt} \%$, the tensile and flexural moduli of PP were increased by about $177 \%$ and $359 \%$, respectively [8]. Xiaochun et al. [11] found that the increase of carbon fibre loadings significantly increased the tensile modulus from 1,500 to $5,000 \mathrm{MPa}$ at $10 \mathrm{wt} \%$ of carbon fibre, while flexural strength and flexural modulus increased from $1300 \mathrm{MPa}-3500 \mathrm{MPa}$ compared to neat PP. At this case, the interface can transfer load more efficiently, which could be the reason for the increase in flexural strength and modulus [11].

One of the major challenges in the area of carbon-fibre PP base- composites is to improve the fibre matrix adhesion and interfacial strength of such composites. This is because the interfacial adhesion has a significant impact on the composite performance. A number of researchers attempted to enhance the properties of carbon-fibre PP based-composite by addition of PP-g-MA, a well-known coupling agent for PP composites which improves the adhesion between phases in composite materials [13]. Moreover, it can increase dispersability of the carbon fibres. This can be used as a compatibiliser for composite blending, as it enhances the interfacial adhesion between the carbon fibre and matrix material via formation of chemical functional groups at the PP/carbon fibre interface by reaction between PP and maleic anhydride (MAH) [14-16]. Therefore, said composites have shown improved performance when the filler content was increased [15]. The addition of carbon fibre related to an increase in the crystallinity and density. Further studies on increasing the carbon fibre content in samples containing PP-g-MAH as compatibiliser indicated the formation of nuclei due to a synergistic effect between PP-gMAH and the carbon fibre [8]. This contributed to the increase in the crystallinity and density [10].

Despite the advantages of carbon fibre as a reinforcing agent, there are some limitations too. The incorporation of carbon fibre into PP material can cause it to become more brittle, with a corresponding dramatic reduction of elongation at break $[8,10,11]$. This is because fillers usually restrict the chain mobility of polymer molecules. Since the polymer chains cannot move freely, the strain at break is reduced with increasing the carbon fibre content [8]. The impact strength is one of the properties that can be reduced, compared to neat polymers, with the increase of weight fraction of carbon fibre, because of the stress concentration regions that can be formed around fillers $[8,10,11]$.

\subsection{Previous studies on PP/kaolin composite}

Kaolin is one of the fillers in the particle family that is widely used as an extremely versatile functional filler. Several reports have revealed that it can improve mechanical properties of thermoplastics such as tensile and flexural moduli. Moreover, kaolin can improve dimensional stability and enhance toughness and rigidity through the restriction in the mobility of the polymer molecules.

The addition of surface-treated kaolin improved the flexural modulus over two times that of the unfilled resin at a loading of $30 \mathrm{wt} \%$, with a small effect on impact strength [6, 17].

Further works reported that PP/kaolin composites showed improved tensile strength, flexural modulus and impact strength [6,17, 18]. Ariffin et al. [18] indicated that PP/kaolin composite with $30 \mathrm{wt} \%$ kaolin showed an enhanced impact strength by up to 47\% [18]. However, one of the major complications of PP/kaolin composites is the possible high level of agglomeration [19]. This is because kaolin is an inorganic rigid material with a high surface energy or high polarity compared to PP which has very low surface energy and polarity $[20,21]$. When kaolin was mixed with hydrophobic PP, the agglomeration of kaolin particles can become crucial. Furthermore, the interfacial adhesion of kaolin particles and PP matrix is also poor [22].

Based on these previous studies, a key challenge in compounding the polymer composites with kaolin is to get uniform dispersion and to avoid agglomeration. Many specialists attempted to solve this by surface modification or treatment to improve compatibility in the polymer matrix [18]. Not only, surface modification, but also the use of coupling agents was 
also explored in order to improve the compatibility between filler and matrix, which is expected to improve the interfacial adhesion characteristic of the polymeric resins [19].

This study aims to evaluate potential methodologies to improve the performance of PP matrix composites by the addition of carbon fibre and kaolin. Carbon fibre and kaolin were processed using a twin screw extruder. The effect of filler types and loading on mechanical properties of extruded PP from neat PP were investigated. Mechanical properties such as the tensile modulus, flexural modulus, and impact strength were evaluated by using universal testing systems.

\section{MATERIALS\& METHODOLOGY}

\subsection{Materials}

Raw materials and reinforcing agents were used in this study are shown in the Tables $1-3$.

Table 1: Melt flow index (MFI) and density of selected resin used in the study

\begin{tabular}{ccc}
\hline Resin (Trade name) & \multicolumn{1}{c}{$\begin{array}{c}\text { MFI } \\
(\mathrm{g} / 10 \mathrm{~min})\end{array}$} & $\begin{array}{c}\text { Density } \\
\left(\mathrm{g} / \mathrm{cm}^{3}\right)\end{array}$ \\
\hline Polypropylene resin (PP resin), (EL-Pro P739ET) & $55^{*}$ & 0.910 \\
Compatibilizer (PP-g-MA), (MAH 1 wt\%) (Polybond 3200) & $115^{* *}$ & 0.910 \\
\hline$*$ MFI tested at $230^{\circ} \mathrm{C}, 2.16 \mathrm{~kg}$ loading $* *$ MFI tested at $190{ }^{\circ} \mathrm{C}, 2.16 \mathrm{~kg}$ loading & &
\end{tabular}

Table 2: Average fibre length and diameter of fibrous fillers

\begin{tabular}{cccc}
\hline Fibre (Trade name) & $\begin{array}{c}\text { Average fibre length } \\
\text { (micron) }\end{array}$ & $\begin{array}{c}\text { Average fibre diameter } \\
\text { (micron) }\end{array}$ \\
\hline Glass fibre & (CS331) & 4,000 & 13 \\
\hline
\end{tabular}

Table 3: Average fibre length and bulk density of particulate fillers

\begin{tabular}{ccc}
\hline Fillers (Trade name) & Average particle size (micron) & Bulk Density $\left(\mathrm{g} / \mathrm{cm}^{3}\right)$ \\
\hline Kaolin (SILFIT Z 91) & 2 & 0.33 \\
\hline
\end{tabular}

\subsection{Preparation of PP composites and sample specimens \\ 2.2.1 Compounding condition}

Table 4: PP composites formulation

\begin{tabular}{|l|c|c|c|c|c|c|}
\hline \multicolumn{1}{|c|}{ Composites } & $\begin{array}{c}\text { PP/KL10 } \\
(\mathrm{wt} \%)\end{array}$ & $\begin{array}{c}\text { PP/KL20 } \\
(\mathrm{wt} \%)\end{array}$ & $\begin{array}{c}\text { PP/KL30 } \\
(\mathrm{wt} \%)\end{array}$ & $\begin{array}{c}\text { PP/CF10 } \\
(\mathrm{wt} \%)\end{array}$ & $\begin{array}{c}\text { PP/CF20 } \\
(\mathrm{wt} \%)\end{array}$ & $\begin{array}{c}\text { PP/CF30 } \\
(\mathrm{wt} \%)\end{array}$ \\
\hline PP & 88.5 & 77 & 65.5 & 88.5 & 77 & 65.5 \\
Kaolin & 10 & 20 & 30 & - & - & - \\
Carbon fibre & - & - & - & 10 & 20 & 30 \\
PP-g-MA & 1.5 & 3 & 4.5 & 1.5 & 3 & 4.5 \\
\hline
\end{tabular}

PP hybrid composites were processed in a Minilab twin-screw extruder (HAAKE, Germany). PP and the fillers were kept in closed containers in the storage room to prevent the moisture adsorption and they were dried again in a vacuum oven at $80{ }^{\circ} \mathrm{C}$ over 15 hours before use. Kaolin and carbon fibre were fed into the extruder by gravimetric feeder (Brabender Lossin-Weight Feeder DDW-MD0-MT-0.5) with twin concave screw. While, raw materials in pellet or rod forms such as neat PP resins, compatibilizer (PP-g-MA) were carefully pre-mixed before feeding into the extruder by a volumetric feeder. These components were mixed in a co - rotating twin screw extruder (Haake Rheomax OS PTW16) at a screw speed of $70 \mathrm{rpm}$ with throughput of $1.8 \mathrm{~kg} / \mathrm{hr}$. The temperature profiles from feed to die direction were 180/190/190/210/210/210/210 $/ 210 / 210 / 180^{\circ} \mathrm{C}$. For composites manufacturing, the PP based hybrid composite were formulated according to Table 4. 


\subsubsection{Specimen fabrication}

Three types of composites specimens were prepared for testing mechanical properties: tensile, flexural and Izod impact testing. All these samples were prepared by injection moulding machines in the different dimensions.

For tensile testing, specimens were prepared by the Minijet injection moulding machine from HAAKE, Germany into dumbbell shaped samples following ISO 527 standard. The process conditions are shown in Table 5.

Table 5: Processing condition parameter of Minijet

\begin{tabular}{|c|c|c|c|c|c|}
\hline \multirow{2}{*}{$\begin{array}{c}\text { Barrel temperature } \\
\left({ }^{\circ} \mathbf{C}\right)\end{array}$} & $\begin{array}{c}\text { Mould } \\
\text { temperature } \\
\left({ }^{\circ} \mathbf{C}\right)\end{array}$ & $\begin{array}{c}\text { Pressure } \\
(\text { bar })\end{array}$ & Time (s) & $\begin{array}{c}\text { Pressure } \\
(\text { bar })\end{array}$ & Time (s) \\
\hline 210 & 45 & 250 & 10 & 100 & 5 \\
\hline
\end{tabular}

In the case of specimens for flexural modulus and Izod impact testing these have to be referred to ISO 178 and ISO 180. Specimens were cut into the standard dimension. The dimension, in millimetres, of the preferred test specimen are length $80 \pm 2 \mathrm{~mm}$, width $10 \pm 0.2 \mathrm{~mm}$, thickness $4.0 \pm 0.2 \mathrm{~mm}$.

Test specimens for Flexural and Izod impact testing were prepared by an injection moulder from Negri Bossi, Italy. The process conditions are shown in Table 6 . The preferred set of condition was maintained at $23^{\circ} \mathrm{C}$ and $50 \%$ of relative humidity.

Table 6: Processing conditions used for injection moulding with Negri Bossi

\begin{tabular}{|c|c|c|c|}
\hline \multirow{2}{*}{ Barrel temperature $\left({ }^{\circ} \mathbf{C}\right)$} & \multirow{2}{*}{ Injection Pressure (bar) } & \multicolumn{2}{|c|}{ Holding step } \\
\cline { 3 - 4 } & & Pressure (bar) & Time (s) \\
\hline $210-210-210-210$ & 42 & 15 & 15 \\
\hline
\end{tabular}

For Izod impact testing, the testing specimens had to be notched. The notch shall be located at the centre of the specimen. The specimens were notched by a notch maker and were prepared as type A [23]. The remaining width at the notch base has to be $8.0 \pm 0.2 \mathrm{~mm}$ [23]. The testing specimens for flexural modulus and Izod impact testing are shown in the Figure 4. Before testing, the specimens had to be conditioned as in the standard ISO 291 for the material being tested.

\subsection{Characterizations}

\subsubsection{Tensile testing}

The tensile tests were performed according to ISO 527 using the Instron 5984 model. Tensile strength and elongation at break were recorded. The test specimen shall be conditioned in the controlled atmosphere is $(23 \pm 2){ }^{\circ} \mathrm{C}$ and $(50 \pm 10) \%$ R.H. The conditioning time is at least 16 hours [24]. The rate used was $50 \mathrm{~mm} / \mathrm{min}$ with $1 \mathrm{kN}$ load by Universal testing machine. Five specimens were tested and the average of the five best measurements was reported. All tests were done under room temperature.

\subsubsection{Flexural testing}

The flexural tests were performed according to ISO 178 using the Instron 5984 model. The procedure used was test method 1 (three-point loading utilizing center loading) with a span width of $64 \mathrm{~mm}$. The dimension of test specimens was width $10 \pm 0.2 \mathrm{~mm}$, length $80 \pm 2 \mathrm{~mm}$ and thickness $4 \pm 0.2 \mathrm{~mm}$. The crosshead rate used was $2 \mathrm{~mm} / \mathrm{min}$ with $1 \mathrm{kN}$ load. This test speed rate of $2 \mathrm{~mm} / \mathrm{min}$ has been referred from ISO 178 which is the speed for the preferred test specimen. The test specimen shall be conditioned in the controlled atmosphere is $(23 \pm 2){ }^{\circ} \mathrm{C}$ and $(50 \pm 10) \%$ Relative humidity. The flexural properties known as flexural strength and flexural modulus were recorded.

\subsubsection{Izod Impact Testing}


For Izod notched impact strength testing, impact energy will be absorbed in breaking a notched specimen, referred to the original cross-sectional area of the specimen at the notch, with the pendulum striking the face containing the notch. The absorbed impact energy is expressed in kilojoules per square metre $\left(\mathrm{kJ} / \mathrm{m}^{2}\right)$. The impact strength of the materials was carried out with pendulum energy of $11 \mathrm{~J}$ by using Instron Ceast 9050 . All specimens had the following dimensions: $10 \times 80 \times 4$ $\mathrm{mm}^{3}$. Notched samples with a span length of $80 \mathrm{~mm}$ were mounted, according to ISO 180 . Five to ten specimens were tested and the average value is given. A set of 10 specimens shall be tested. However, if the coefficient of variation (CV) less than $5 \%$, a minimum number of five test specimens is sufficient. All tests were done under room temperature.

\section{Results And Discussion \\ 3.1 Tensile properties}

The results of tensile strength at yield, tensile strength at break and tensile modulus were tested following ISO 527 [24]. At least five specimens from each formulation were tested. From the Figure 1 represents the tensile modulus of virgin PP (vPP), PP composites with different amount of fillers.

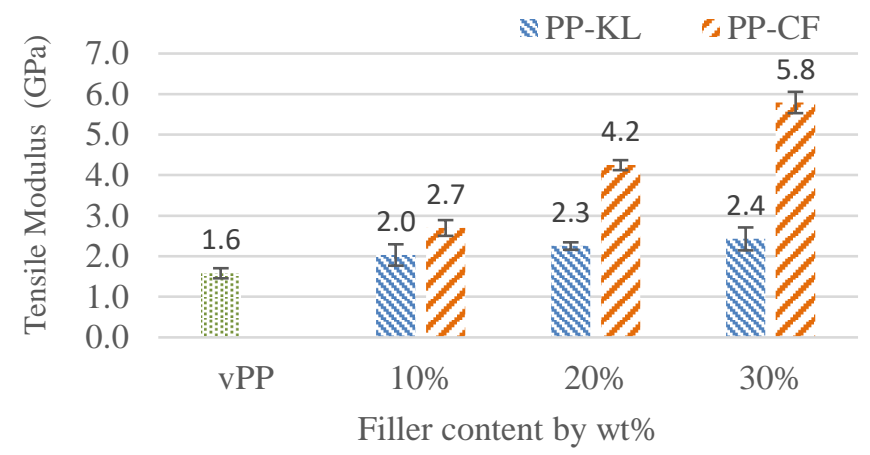

Fig.1: The effect of filler types and content on tensile modulus

From the particle family, composites formed by addition of kaolin were evaluated. The problem that was frequently found was poor interfacial adhesion between the filler surface and the matrix. This is another factor that affects tensile modulus. Kaolin has a highly polar hydrophilic surface, whereas the polymer (such as PP, PE, etc) is non-polar and hydrophobic. This led to some difficulty in achieving uniform dispersion of the filler. The poor interaction between filler and polymer matrix led to a tendency of large agglomeration, which can influence the mechanical properties of the finished composite [25]. To overcome this limitation, addition of PP-g-MA as compatibiliser was applied in order to promote the interfacial adhesion between polymer matrix and fillers in this project. This was due to the formation of covalent linkages and hydrogen bonds between the maleic anhydride and the functional groups on fillers [25]. Previous works have reported an improvement in mechanical properties of composites after adding PP-g-MA [25, 26].

The improvement in tensile modulus is commonly attributed to the rigidness of fillers, such as kaolin which is a mineral more inherently stiff and rigid than the PP matrix. The incorporation of these fillers can influence the stiffness of the whole bulk of composite by restricting the mobility of polymer molecules [17, 25, 27]. Considering the Figure 1, increasing carbon fibre content from 10 - $30 \mathrm{wt} \%$ increased the tensile modulus of PP composite. The addition of $10 \mathrm{wt} \%$ of carbon fibre resulted in an increase of the tensile modulus of about $77 \%$ as compared with that of neat PP. These results can be understood by referring to interfacial bonding and stress transfer along fillers. Normally, the interfacial bonding between fibres and PP matrix is weak. This is mainly because there are less reactive groups on the carbon fibres, which can improve the fibre/matrix interfacial adhesion. As for the case of kaolin, here we also overcome this limitation by the addition of compatiblizer for these experiments with carbon fibres. The presence of PP-g-MA is expected improve the interfacial adhesion between PP and fibre, resulting in a further improvement in tensile.From the Figure 2, elongation at break of neat PP and PP based composites have been shown. 


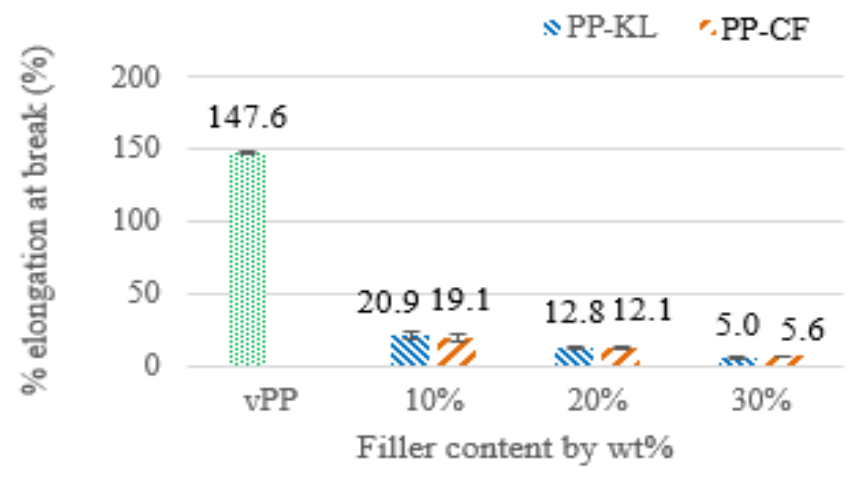

Fig.2: The effect of filler types and content on the percentage of elongation at break (\%)

The percentage of elongation at break of PP composites from kaolin was dramatically reduced compare to neat PP. Generally in the particulate filler, the decrease in elongation was also an effect of the increment of the stiffness and rigidity of composites by the incorporation of rigid fillers. These rigid particles limited the movement of the PP macromolecule chains and weakening the ability to cope with external forces, resulting in an increase in the brittleness of the composites $[17,25]$. Moreover, the agglomerations of these fillers in high concentration acted as stress concentrators and obstruct the ability for stretching of the polymer matrix $[17,25]$. However, it can be noted that increasing the kaolin filler content from $10-30 \mathrm{wt} \%$, the elongation at break of composite declined significantly.

For the PP fibrous composites there is a similar reduction in the elongation at break when the carbon fibre loading is increased from $10 \mathrm{wt} \%$ to $30 \mathrm{wt} \%$. This is because the rigid fibres hinder the movement of polymer chains so the chains cannot move freely. The elongation at break was reduced with increasing fibre content [15].

\subsection{Flexural properties}

Flexural testing of the near polymer and the composites was performed to assess the ability of a material to resist deformation under a bending load. The results of flexural strength and flexural modulus are shown in Figure 3 . The testing of the specimens were conducted following the standard ISO 178 [28].

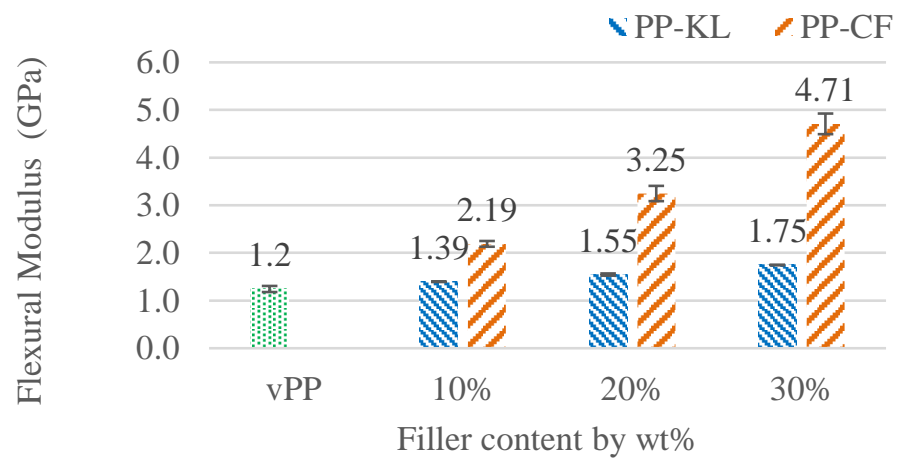

Fig.3: The effect of filler types and content on flexural modulus

The measured flexural modulus closely followed the trend observed for the tensile modulus described above Minor differences in their scaling are due to the differences of deformation mode (three-point bending in flexural testing and vs. failure under extension in tensile), shape and dimensions of the samples (flex bars vs. dog-bone shape samples), etc [29].

For the particle reinforced composites, it was observed an improvement of flexural modulus which is attributed to the reinforcing kaolin materials being more rigid than PP $[18,20]$. These particles can enhance rigidity of composites comparing to extruded neat PP. For the three different filler contents explored, $10 \mathrm{wt} \%$ to $30 \mathrm{wt} \%$, the improvement in 
flexural modulus relative to neat PP was within a range of $14-50 \%$. These levels of improvement already indicate a strong interfacial adhesion between fillers and the matrix.

On the other hand, for composites based on carbon fibre the flexural modulus was raised by up to a fourfold when increasing filler content $[10,14,30]$. The added fibres with good adhesion with the polymer matrix act as the load carrier where stress can be transferred from the polymer matrix, which can lead to stress distribution within the composite [10, 31]. From the results of tensile and flexural moduli, it can be found that the addition of rigid fillers to the polymer matrix enhances both tensile and flexural properties, including stiffness of composites. However, these properties can be better improved by using small particles with uniform distribution and dispersion. This is because small particles have more surface area to adhere strongly to the polymer matrix which can lead to a strong reinforcing effect. On the other hand, a problem with very fine particles is that they can adhere strongly to each other and form agglomerations. These can lead to the initiation of failure sites. The using of coupling agent and surface treatment can assist to reduce particle-particle interaction and prevent the formation of agglomerated structures [32].

\subsection{Izod impact properties}

The testing specimens were conducted the impact testing follow ISO 180 [20]. Izod impact testing is one of methods to determine the toughness of materials by measuring the energy required to propagate a crack rapidly. This test test normally only involves the plane directly ahead of the notch tip where, in a material with low level of plastic response, the fracture becomes unstable. Whereas, tensile test is a slower test that eventually probes the whole gauge volume of the specimen. Moreover, the presence of the notch can impose a much higher velocity which results in a large value of local strain rate in the Izod impact testing experiment, with larger magnitude than in the tensile test. Therefore, it is not surprising that the two toughness measurements present quite different trends [33]

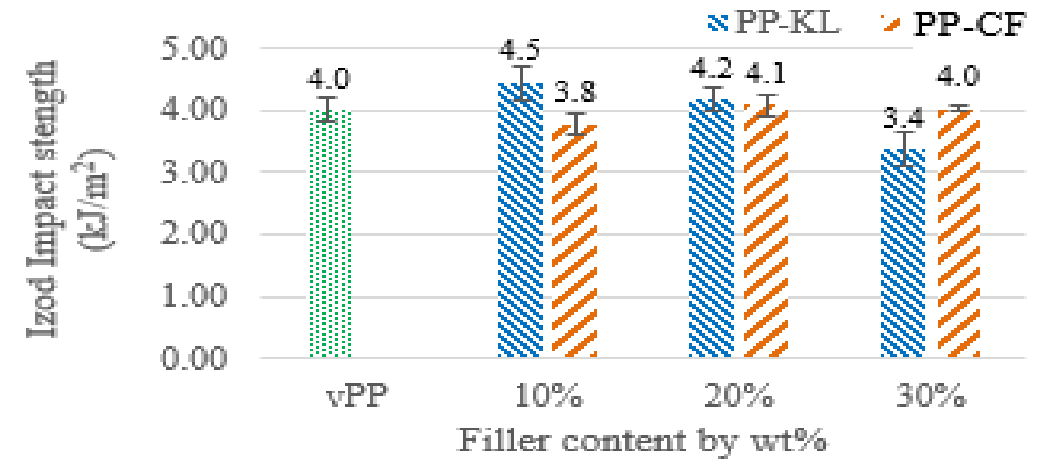

Fig.4: The effect of filler types and content on Izod impact strength

For the kaolin filler, it was found that the impact strength of PP/kaolin was initially moderately increased by addition of kaolin at $10 \mathrm{wt} \%$. Subsequently, it was moderately reduced when increasing kaolin content from $10 \mathrm{wt} \%$ to $30 \mathrm{wt} \%$. The largest decrease in impact strength occured from PP/kaolin at $20 \mathrm{wt} \%$ to $30 \mathrm{wt} \%$, i.e. from $4.2 \mathrm{~kJ} / \mathrm{m}^{2}$ to $3.4 \mathrm{~kJ} / \mathrm{m}^{2}$. We attribute this to kaolin being an inorganic rigid particle with high surface energy which, when mixed with hydrophobic PP, led to a serious level of agglomeration for high filler content [22]. Said agglomeration leads not only to an increase in the brittleness, but it also creates many crack initiations and stress-concentration sites. These can become weak point of composites which were very sensitive to impact stresses and cause detrimental effects on the impact properties of the composite [34]. Furthermore, the interfacial adhesion of kaolin particles and PP matrix is small, which becomes the weak point of composite materials. Although PP-g-MA was added as the coupling agent, a high shear from the extruder would be required to reduce the level of agglomeration, especially for high filler content.

In the case of PP/carbon fibre composites, we observe a different trend, mostly flat. The impact strength slightly increases when increasing the carbon fibre content from $10 \mathrm{wt} \%$ to $20 \mathrm{wt} \%$ and then remains essentially constant when increase to $30 \mathrm{wt} \%$. Therefore we observe no significant reinforcement effect with addition of carbon fibre, compared with 
neat PP, when adding $10 \mathrm{wt} \%$ fibre content. Only when increasing the carbon fibre content to $20 \mathrm{wt} \%$ we observe that the , impact strength recovers and reached the highest at $4.1 \mathrm{~kJ} / \mathrm{m}^{2}$. This result can support the previous study that was investigated by Kumar D. T. et al. [14]. This is due to this rigid filler and the creation of stress region concentrations at the ends of fibres is another reason for crack formation in the matrix around the carbon fibres. This required less energy to initiate the cracking propagation and the resulting microcracks propagated, therefore inhibiting an increase, and even reducing, the resistance to impact $[8,15]$.

From the experimental results of PP based composite with kaolin and carbon fibre, it can be found that PP/carbon fibre composite had the outstand performance on tensile and flexural modulus which were more superior than PP/kaolin. However, the kaolin filled PP composite can be found that impact strenght was improved to be better than neat PP in low kaolin content $(10 \mathrm{wt} \%)$. While the incorperation of carbin fibre couldn't improve the impact strenght sighinificantly. It can be seen that, these fillers have the benefit in different aspects so the concept of hybrid composite by combined these fillers is so interesting. The synergistic effectes of these two fillers should be further investigated.

\section{Conclusions}

This study aimed to evaluate potential methodologies to improve the performance of PP matrix composites by the addition of carbon fibre and kaolin. Carbon fibre and kaolin were processed using a twin screw extruder. The effect of filler types and loading on mechanical properties of composite PP and neat PP were investigated. Mechanical properties such as the tensile modulus, flexural modulus, and impact strength were evaluated by using universal testing systems.

Of the two types of composites, carbon fibre reinforced composites gave the best performance. Our results showed that the addition of $30 \mathrm{wt} \%$ of short carbon fibre to neat PP raised the tensile modulus and flexural modules by $263 \%$ and $293 \%$ respectively, compared to neat PP itself. The elongation results also support this observation, showing a reduced elongation at break by $87-96 \%$ compared to neat PP, consistent with a restricted chain mobility. On the other hand, regarding impact strength we observed no significant reinforcement effect with addition of carbon fibre compared with neat PP.

Kaolin still offered an enhanced performance for both tensile and flexural moduli with respect to that of neat PP. These results, also associated to restricted molecular mobility, are correlated with a significant reduction of the elongation at break by more than $80 \%$ with increasing kaolin content. According to the Izod impact test, the addition of kaolin can moderately improve impact strength by $10 \%$ at low content of kaolin, $10 \mathrm{wt} \%$. However, the impact strength was reduced with increasing kaolin content above $20 \mathrm{wt} \%$, consistent with previous work showing that the agglomeration of kaolin particles can weaken the composite [8].

Overall, both the addition of carbon fibre and kaolin from 10-30\% by weight significantly improve the tensile and flexural modulus properties compared with neat PP, with the PP/carbon fibre composite exhibiting a performance superior to PP/kaolin. However, the kaolin filled PP composite showed a moderate increase in impact strenght, compared to neat PP, for low kaolin content (10 wt\%), whereas the incorperation of carbon fibre did not significantly change the impact strenght. Therefore these fillers offer distinct benefits regarding mechanical properties, which raises interesting prospects for the development of hybrid composites where the potential synergistic effectes of these two fillers could be further investigated. Both fillers can be considered as promising alternative for reinforcing materials to increase the performance of thermoplastics. These composite systems may encourage commodity thermoplastics to be applied for high-end applications at a significant rate in the near future.

\section{Acknowledgments}

The support provided by the Technical Staff of the Northwest Composites Centre at the University of Manchester is greatly appreciated. 


\section{References}

[1] C. Abeykoon, A. McMillan, C. Dasanayaka, X. Huang, and P. Xu, "Remanufacturing using End-of-Life Vehicles and Electrical and Electronic Equipment Polymer Recyclates-A Paradigm for Assessing the Value Proposition," International Journal of Lightweight Materials and Manufacture, 2021.

[2] C. Abeykoon, A. McMillan, and B. K. Nguyen, "Energy efficiency in extrusion-related polymer processing: A review of state of the art and potential efficiency improvements," Renewable and Sustainable Energy Reviews, vol. 147, p. $111219,2021$.

[3] R.-M. Wang, S.-R. Zheng, and Y. G. Zheng, Polymer matrix composites and technology. Elsevier, 2011.

[4] J. Zhu, C. Abeykoon, and N. Karim, "Investigation into the effects of fillers in polymer processing," International Journal of Lightweight Materials and Manufacture, vol. 4, no. 3, pp. 370-382, 2021.

[5] S. K. Gopalraj and T. Kärki, "A review on the recycling of waste carbon fibre/glass fibre-reinforced composites: fibre recovery, properties and life-cycle analysis," SN Applied Sciences, vol. 2, no. 3, pp. 1-21, 2020.

[6] J. Duca, "Kaolin," Functional Fillers for Plastics, pp. 221-239, 2005.

[7] M. Tawfik, N. Ahmed, and A. Ward, "Characterization of kaolin-filled polymer composites," 07/15 2018, doi: 10.2417/spepro.004978.

[8] D. Pérez-Rocha, A. Morales-Cepeda, F. Navarro-Pardo, T. Lozano-Ramírez, and P. G. Lafleur, "Carbon fiber composites of pure polypropylene and maleated polypropylene blends obtained from injection and compression moulding," International Journal of Polymer Science, vol. 2015, 2015.

[9] H. Y1lmaz, Y. Imai, K. Nagata, K. Sato, and Y. Hotta, "Localized thermal analysis of carbon fiber-reinforced polypropylene composites," Polymer composites, vol. 33, no. 10, pp. 1764-1769, 2012.

[10] L. Altay, M. Atagur, O. Akyuz, Y. Seki, I. Sen, M. Sarikanat, K. Sever, "Manufacturing of recycled carbon fiber reinforced polypropylene composites by high speed thermo-kinetic mixing for lightweight applications," Polymer Composites, vol. 39, no. 10, pp. 3656-3665, 2018.

[11]Y. Xiaochun, Y. Youhua, F. Yanhong, Z. Guizhen, and W. Jinsong, "Preparation and characterization of carbon fiber/polypropylene composites via a tri-screw in-line compounding and injection molding," Advances in Polymer Technology, vol. 37, no. 8, pp. 3861-3872, 2018.

[12] C.-L. Huang, C.-W. Lou, C.-F. Liu, C.-H. Huang, X.-M. Song, and J.-H. Lin, "Polypropylene/graphene and polypropylene/carbon fiber conductive composites: mechanical, crystallization and electromagnetic properties," Applied Sciences, vol. 5, no. 4, pp. 1196-1210, 2015.

[13] G. Pritchard, Plastics additives: an AZ reference. Springer Science \& Business Media, 2012.

[14] A. Dt, K. Prasad, and P. Rao, "Study of Mechanical Properties of Carbon Fiber Reinforced Polypropylene," International Journal of Engineering Research and, vol. V4, 10/26 2015, doi: 10.17577/IJERTV4IS100500.

[15] N. G. Karsli and A. Aytac, "Effects of maleated polypropylene on the morphology, thermal and mechanical properties of short carbon fiber reinforced polypropylene composites," Materials \& Design, vol. 32, no. 7, pp. 4069-4073, 2011.

[16] H.-I. Kim, W. Han, W.-K. Choi, S.-J. Park, K.-H. An, and B.-J. Kim, "Effects of maleic anhydride content on mechanical properties of carbon fibers-reinforced maleic anhydride-grafted-poly-propylene matrix composites," Carbon letters, vol. 20, pp. 39-46, 2016.

[17] S. Maiti and B. Lopez, "Tensile properties of polypropylene/kaolin composites," Journal of applied polymer science, vol. 44, no. 2, pp. 353-360, 1992.

[18] A. Ariffin, A. Mansor, S. Jikan, and Z. Mohd. Ishak, "Mechanical, morphological, and thermal properties of polypropylene/kaolin composite. Part I. The effects of surface-treated kaolin and processing enhancement," Journal of applied polymer science, vol. 108, no. 6, pp. 3901-3916, 2008.

[19] N. A. Rahim, Z. Ariff, A. Ariffin, and S. Jikan, "Study on effect of filler loading on the flow and swelling behaviors of polypropylene-kaolin composites using single-screw extruder," Journal of Applied Polymer Science, vol. 119, no. 1, pp. 73-83, 2011. 
[20] A. Helmy, E. Ferreiro, and S. De Bussetti, "The surface energy of kaolinite," Colloid and Polymer Science, vol. 283, no. 2 , pp. 225-228, 2004.

[21] E. Chibowski and K. Terpilowski, "Surface free energy of polypropylene and polycarbonate solidifying at different solid surfaces," Applied surface science, vol. 256, no. 5, pp. 1573-1581, 2009.

[22] J. Yao, H. Zhu, Y. Qi, M. Guo, Q. Hu, and L. Gao, "Tough and Reinforced Polypropylene/Kaolin Composites using Modified Kaolin," in IOP Conference Series: Materials Science and Engineering, 2018, vol. 359, no. 1: IOP Publishing, p. 012034.

[23] I. S. Organization, "ISO 180: 2000-Plastics--Determination of Izod impact strength," ed: ISO Geneva, 2000.

[24] E. ISO, "527-2: 2012," Plastics-Determination of tensile properties-Part, vol. 2, 2012.

[25] H. Salmah, C. Ruzaidi, and A. Supri, "Compatibilisation of polypropylene/ethylene propylene diene terpolymer/kaolin composites: the effect of maleic anhydride grafted-polypropylene," Journal of Physical Science, vol. 20, no. 1, pp. 99107, 2009.

[26] N. Yang, Z. C. Zhang, N. Maa, H. L. Liu, X. Q. Zhan, B. Li , W. Gao, F. C. Tsai, T. Jiang, C. J. Chang, T. C. Chiang, D. Shi, "Effect of surface modified kaolin on properties of polypropylene grafted maleic anhydride," Results in physics, vol. 7, pp. 969-974, 2017.

[27] J. Al-Sabea, "Tensile and Compressive Properties of Kaolin Rienforced Epoxy," 10/01 2015.

[28] B. ISO, "178: 2010," Plastics-Determination of flexural properties (ISO 178: 2010), 2010.

[29] K. Kalaitzidou, H. Fukushima, H. Miyagawa, and L. Drzal, "Flexural and tensile moduli of polypropylene nanocomposites and comparison of expermental data to Halpin-Tsai and Tandon-Wang models," Polymer Engineering \& Science, vol. 47, pp. 1796-1803, 11/01 2007, doi: 10.1002/pen.20879.

[30] R. B. Yunus, N. Zahari, M. Salleh, and N. A. Ibrahim, "Mechanical properties of carbon fiber-reinforced polypropylene composites," in Key Engineering Materials, 2011, vol. 471: Trans Tech Publ, pp. 652-657.

[31] M. Szpieg, "Development and characteristics of a fully recycled CF/PP composite," Luleå tekniska universitet, 2011.

[32] A. Sjögren, "Failure behaviour of polypropylene/glass bead composites," Luleå tekniska universitet, 1995.

[33] Y. Thio, A. Argon, R. Cohen, and M. Weinberg, "Toughening of isotactic polypropylene with CaCO3 particles," Polymer, vol. 43, no. 13, pp. 3661-3674, 2002.

[34] Y. Leong, M. Abu Bakar, Z. M. Ishak, A. Ariffin, and B. Pukanszky, "Comparison of the mechanical properties and interfacial interactions between talc, kaolin, and calcium carbonate filled polypropylene composites," Journal of Applied Polymer Science, vol. 91, no. 5, pp. 3315-3326, 2004. 